\title{
Audiovideonota: o audiovisual como registro de um processo de criação em percurso
}

Daniel Rojas da Silva ${ }^{1}$

\section{Introdução}

Ao início do estudo de um processo de criação, se mostram necessários documentos que comprovem ou que venham a apresentar tal processo em questão. Se tratando de um estudo do próprio processo, recorremos à metodologia autoetnográfica como proposta por Sylvie Fortin ${ }^{2}$. Este estudo pretende lançar olhar à própria prática artística em percurso já traçado, estabelecer fundamentação teórica e artística e, por fim, conceitualizar de que maneira a documentação desta prática está sendo realizada e materializada. Trazemos junto conosco Cecília Salles para pensarmos o processo criativo, suas possibilidades e a potência do gesto criador como ato necessário à vida do artista.

No intuito de formalizar o processo de criação em questão, o comparamos aos filmes-diário do cineasta Jonas Mekas, que, ao filmar, registrava seu cotidiano e sua vida. Por consequência, registrou longos períodos em seus filmes e tais registros compuseram grande parte de sua obra filmográfica. Sugerimos um método de registro ${ }^{3}$ semelhante para a documentação de processo, o qual chamamos aqui de audiovideonota (com todas as palavras juntas e sem acento) e que se relaciona com a filmografia de Mekas, na medida em que - e como registro de processo criativo - utiliza do ato de gravar para registrar as mais diversificadas situações em seu cotidiano. Associamos o vídeo à camada sonora, que com frequência traz Mekas comentando as imagens e acontecimentos. O realizamos como comentários e reflexões verbalizadas e gravadas a respeito do trajeto de criação. Justificamos tal processo criativo como parte integrante de um trabalho maior. As descrições e análises colocadas se referem ao método específico elaborado pelo autor para coletar registros de processo de obra audiovisual em criação. Igualmente, nos debruçaremos sobre as possibilidades sonoras dessa maneira de documentar. A partir desse momento, utilizarei a primeira pessoa do singular, por se tratar de processo relativo à minha própria vivência e minhas experiências.

Ao abordar os processos de criação, é válido propormos essa forma de processo como algo que não se apresenta como vontade racionalizada, mas como impulso necessário advindo do indivíduo que cria. O processo criativo está para a criação assim como a criação está para o criador, como aponta Deleuze: "Um criador não é um ser que

\footnotetext{
${ }^{1}$ Mestrando, aluno do PPGCineAV (UNESPAR), daniel.silva_sk8@hotmail.com.

${ }^{2}$ FORTIN, S. Contribuições possíveis da etnografia e da auto-etnografia para a pesquisa na prática artística. Revista Cena, n. 7, 2009.

${ }^{3}$ Ao utilizar a palavra registro me refiro principalmente ao ato de gravar como captura e consequente registro da realidade objetiva. Priorizo o uso do conceito de ‘documentação de processo' sugerido por Cecília Salles (SALLES, 2008, p. 17) ao me referir a essa metodologia e seus objetos, mas também pode aparecer sob a cunha de documento.
} 
revista de crítica genética

trabalha pelo prazer. Um criador só faz aquilo de que tem absoluta necessidade." ${ }^{4}$ Assim como o criador necessita produzir ou criar aquilo que é inato a si, a criação carrega inevitavelmente algum traço, aspecto do processo que a levou a seu estágio presente. Esta afirmação do autor baseia este texto na medida em que desenvolvo um método de registro para determinado processo criativo de uma obra audiovisual, pois integro o processo à criação em audiovisual.

\section{Mekas: filmando a vida}

É partindo dos documentos de processo que trazemos à luz o artista Jonas Mekas e sua obra como fonte de inspiração e de referência audiovisual. A aproximação de Mekas às câmeras e ao ato de gravar se deu principalmente após sua chegada aos Estados Unidos, para onde teve de emigrar após ter sido preso em campos de concentração durante a Segunda Guerra Mundial juntamente com seu irmão. Mekas menciona que como se sentia deslocado na nova sociedade em que adentrara, usou do recurso da gravação audiovisual como método de registro e forma de comunicação, inserindo-se assim, naturalmente, na cena artística local ${ }^{5}$. Entretanto, Mekas inicialmente procura gravar filmes mais convencionais, ao mesmo tempo em que - despretensiosamente - faz o que podemos chamar de 'diário em filme', que segundo Valles são:

como os registros fílmicos que Mekas realizou de forma integrada à práxis da sua vida e que - pelo menos num primeiro momento - não foram concebidos para virem a se tornar um filme, mas uma prática que recusou tanto um uso comercial como vanguardista sobre esses arquivos. O diário em filme constitui-se, assim, num registro audiovisual de fragmentos da vida íntima e cotidiana do autor, os quais não revelam um sentido de obra, mas um fluxo contínuo de imagens inseridas na sua esfera privada. (VALLES, 2018, p. 100-101)

Como alguém que grava, me identifico completamente com tal modo de registro e percebo que as gravações "aleatórias" que realizo cotidianamente circundam um imaginário próprio a mim mesmo e a minha rotina. Muitas vezes tais gravações captam aspectos singelos do cotidiano e podem vir a integrar parte de algum projeto em vídeo posterior, o que percebi que ocorreu com frequências em muitos de meus vídeos dos últimos dez anos. Como acumulador de imagens em movimento me identifico e me relaciono a Jonas Mekas. Não só documentarista, mas realizador, Mekas veio posteriormente a combinar essas séries de registros que gerou ao longo dos primeiros anos nos Estados Unidos, incentivado por amigos e quando percebeu a quantidade de imagens que havia gravado durante esse tempo:

Por volta de 1961 ou 1962, vi pela primeira vez todo o material que tinha coletado durante todo aquele tempo. Ao ver aquele material antigo, notei que havia várias conexões nele. As sequências que considerava totalmente desconectadas de súbito começaram a parecer um caderno de notas com muitos fios unificadores, mesmo

\footnotetext{
${ }^{4}$ DELEUZE, G. O ato de criação. São Paulo: Folha de São Paulo, 1999, Caderno Mais!, p. 3.

${ }^{5}$ MOURÃO, P. Salve Jonas. In.: Jonas Mekas. São Paulo: Centro Cultural Banco do Brasil; Pró-reitoria de Cultura e

Extensão Universitária - USP, 2013, p. 12-13
} 
revista de crítica genética

naquela forma desorganizada. [...] Enquanto estudava esse material e pensava sobre ele, tornei-me consciente da forma de um filme-diário e, é claro, isso começou a afetar minha maneira de filmar, meu estilo. E em certo sentido isso me ajudou a ter paz de espírito. (MEKAS, 2013, p. 132)

Mekas trabalha com o conceito do filme-diário, que à primeira vista se caracterizaria como uma espécie de seleção, organização e relação desses registros audiovisuais. Esse modo fílmico pode, ao passo que possui características de imagens diversas entre si, se desenvolver de maneira narrativa, ordenando as variadas documentações em vídeo a fim de uma edição final e a finalização do filme. O diretor organiza seus filmes-diários muitas vezes como capítulos, intitulando-os a partir de datas, acontecimentos, comemorações, viagens etc., acentuando o caráter de recordações suscitado.

Recorro aqui ao curta do diretor 'Song of Avignon' (1998) como exemplo deste modo de fazer fílmico citado e como direcionamento formal para os registros das audiovideonotas. O curta-metragem diverge consideravelmente do formato documental narrativo através da entrevista, para recorrer a um monólogo constante e ritmado expondo pensamentos e sentimentos do diretor relacionados às imagens do filme. Ao final escutamos uma música tocada no acordeão, gravada pelo próprio Mekas, que sabia tocar o instrumento e no filme aparece tocando-o (Figuras 1 e 2). Podemos notar através das duas imagens uma diferença da natureza da própria imagem: ao passo que a primeira imagem, com um tom de fundo mais avermelhado, traz uma estética mais característica às fotos analógicas, retratando momentos do cotidiano etc.; enquanto a segunda imagem possui uma coloração mais azulada e está mais próxima a uma estética de selfies, dos vlogs pela proximidade do diretor à câmera e o enquadramento selecionado. Esta diferença aparente nas imagens ajuda a reforçar a ideia de registros diversificados da vida, similarmente a um diário, acompanhamos imparcialmente os dias bons e ruins daquele que filma. Apesar de haver uma discrepância formal ao apresentar tais registros da vida, se tratam sempre de registros.

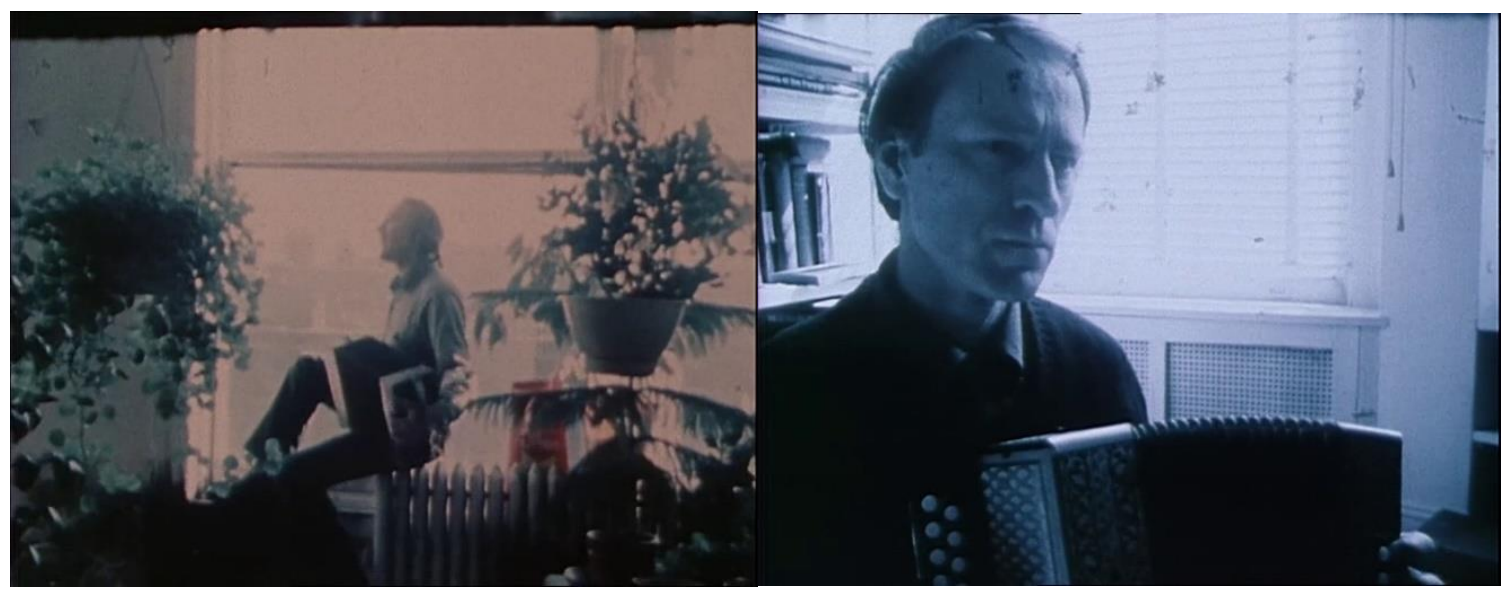

Fig. 1 e 2. Jonas Mekas, frames de 'Song of Avignon', 1998. (SONG of Avignon, 1998).

Além de utilizar - conscientemente ou não - variadas formas estéticas, Jonas Mekas também utilizou registros audiovisuais mais abstratos, como por exemplo as imagens de luzes ou formas abstratas presentes em seu cotidiano (Figura 3). Também recorreu ao uso de texto (Figura 4), o que acabou por incorporar grande parte de seu trabalho 
revista de crítica genética

fílmico de forma poética ou mesmo indicando títulos de capítulos dentro de seus filmes a partir de datas, acontecimentos, comemorações, viagens etc.
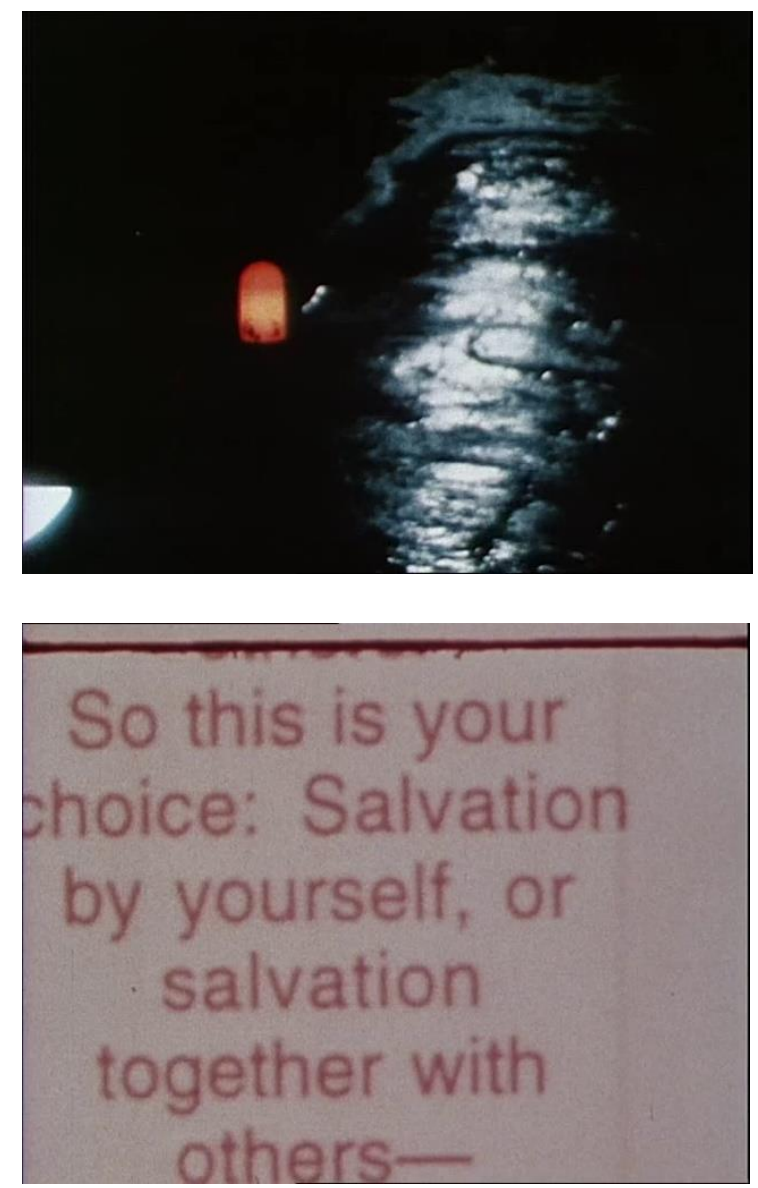

Figura 3. Jonas Mekas, frame de 'Song of Avignon' (abstração visual do reflexo das luzes noturnas na rua molhada, junto com luzes dos carros), 1998. (SONG of Avignon, 1998).

Figura 4. Jonas Mekas, frame de 'Song of Avignon', 1998. (SONG of Avignon, 1998)

A camada sonora do curta-metragem nos apresenta num primeiro momento o próprio diretor discorrendo de forma monotônica e compassada sobre seus sentimentos e emoções enquanto assistimos a imagens de uma noite de tempestade através de uma janela de apartamento e as luzes noturnas da cidade. De certa maneira, as exposições verbais do diretor neste e em outros de seus trabalhos confluem para que o espectador perceba uma crescente compreensão do processo criativo do diretor, levando em consideração os comentários que realiza sobre sua própria vida e sobre os aspectos relativos aos seus filmes. Neste trecho inicial Jonas Mekas expõe:

Hoje percebi que tenho quarenta anos e que um vazio imenso cerca a mim e a minha alma. Eu cheguei a isso, é aqui que minha vida me trouxe. Estou em uma escuridão doentia. Com frequência sinto que estou afundando, procuro pelo ar e sinto hoje que a única saída é submergir, talvez completamente nessa escuridão, 
revista de crítica genética

como num coma. Não correr para longe disso, não contemplar, mas abraçá-la [...] (SONG of Avignon, 1998) ${ }^{6}$

A associação entre imagens e sons produz o efeito singular dos filmes-diário em quem assiste: é como ler um caderno de anotações e rabiscos em formato audiovisual. Relacionamos a forma de registro sonoro em Song of Avignon às notas em áudio que serão utilizadas na composição das audiovideonotas. Ambas as formas de gravação sonora trazem a voz como elemento principal, relatando aspectos que giram em torno da vida daquele que os cria: em Mekas através de reflexões sobre chegar aos quarenta anos, sua vida, suas relações pessoais, nas audiovideonotas através de comentários sobre o processo criativo em desenvolvimento, suas problemáticas, seus aspectos intrínsecos.

Os filmes-diário são como processos de reflexão a respeito do tempo: tempo decorrido entre os acontecimentos expostos no filme, tempo do próprio filme e tempo de vida dos eventos representados. Ao mesmo tempo que são documentos, refletem sobre os processos da pessoa que os cria ${ }^{7}$. Durante o período de criação de tais obras, a realidade do artista pode afetar como o processo criativo ocorrerá, guiando-o a reflexões ou mesmo ações com potencial para mudar a criação completamente ou continuar com o planejamento inicial. O processo de criação se apresenta instável e sem rumo definido, até que a obra em formação caminhe em direção a seu estágio final ${ }^{8}$. Salvas as analogias estéticas e a conceituação dos filmesdiários baseados na forma de fazer fílmico apresentada por Jonas Mekas, podemos notar como esse gênero audiovisual apresenta potencialidades direcionadas a um projeto estético particular a cada artista, e em amplitude ao seu projeto poético. E sincronicamente é composto de registros mais orgânicos e relacionados a um olhar para o banal, para a poesia na recorrência.

Proponho então uma nova nomenclatura, uma possibilidade reconfigurada para o fazer audiovisual, excluindo toda e qualquer pretensão de estar criando algo original e sim incorporando minha própria individualidade ao processo de criação. Audiovideonota é o nome que designei para esta forma específica de registro audiovisual.

\section{A audiovideonota}

Áudio: do latim audio, primeira pessoa do presente do indicativo do verbo audire (ouvir). Vídeo: do latim video, primeira pessoa do presente do indicativo do verbo videre (ver) ${ }^{9}$. Nota: uma anotação, um registro,

\footnotetext{
${ }^{6}$ Tradução nossa. Do original: "Today I realized that I am forty and that an immense emptiness surrounds me and my soul. I have come to this, it is here that my life has led me to, I am in a sick darkness. Often I feel I am sinking, I reach for air and I feel today that the only way out, my only hope, is to submerge perhaps into this darkness completely, like into a coma, not to run Away from it, not to stare into it, but to embrace it [...]”. Trecho inicial do curta 'Song d'Avignon'. (SONG, 1998)

${ }^{7}$ VALLES, R. R. Narrar o vivido, viver o narrado: a construção do diário na obra de Jonas Mekas. Porto Alegre, 2018, p. 101-102.

${ }^{8}$ SALLES C. A. Gesto Inacabado: Processo de Criação Artística. São Paulo: Annablume, 2008, p. 39-40.

${ }^{9}$ Traduções obtidas na apostila de Latim Básico relativa ao $2^{\circ}$ semestre do curso de graduação de Letras em Português da Universidade Federal de Santa Maria (MARASCHIN, 2013, p. 29-30).
} 
revista de crítica genética

um elemento que traz consigo potencialmente a regeneração de uma memória. Trata-se de ouvir, ver e documentar. Elaborei esta nomenclatura a partir da etimologia básica de palavras como costumo fazer para a criação de nomes, procurando auxiliar na compreensão do que é o elemento nomeado. Partindo desta descomplicada conceituação inicial posso então atentar às questões processuais de como esta ideia surgiu e como seus vestígios têm sido colhidos para a presente documentação.

Ao início do processo criativo, mostrou-se necessária a seleção de um método para documentá-lo. Recorri então aos tipos de documentos de processo que são comumente utilizados. Devido à familiaridade que tenho com arquivos de áudio e por sugestão de minha orientadora, pensei sem demora em utilizar arquivos de áudio gravados com celular, prática que já mantenho há anos gravando arquivos dos mais variados (paisagens sonoras, músicas e rascunhos de músicas, arquivos de voz etc.). Após ponderações e reflexões em conversas de orientação decidi trabalhar com a ideia de audionota e comecei no mesmo momento a gravar as audionotas referentes ao que estava ocorrendo em meu processo de criação de 190_lfa: a obra audiovisual em criação. Logo após a gravação dessa primeira audionota, parti de casa para o local de gravações - uma casa em ruínas - e comecei a capturar imagens de maneira impulsiva e frenética, gravando por toda a parte, procurando captar cada peculiaridade estética da casa.

Junto aos arquivos de áudio, senti necessidade do elemento visual que viria a apresentar este 'vídeo' e que experiencio quando estou nestes momentos de imersão no processo criativo de 190_lfa, seja nos momentos em que gravei imagens e áudios para a obra ou mentalmente conceituando-a através de ideias. A conceituação que havia realizado anteriormente de guia para o filme associada às primeiras imagens e áudios que captei como documentação de processo auxiliaram-me a compreender a fluidez do processo de criação: "a tendência (do processo criativo) é indefinida, mas o artista é fiel a essa vagueza. O trabalho caminha para um maior discernimento daquilo que se quer elaborar. A tendência não apresenta já em si a solução concreta para o problema, mas indica o rumo" ${ }^{10}$. Posteriormente percebi que esse impulso inicial de registros de processo operou como uma ferramenta para que iniciasse a produção de 190_lfa, finalizada a etapa de pesquisa da obra.

\subsection{Audio}

O aplicativo de celular utilizado para gravar os áudios é o Easy Voice Recorder, uma aplicação comum e gratuita que possui boa qualidade de áudio. Os arquivos foram renomeados como "diário projeto (número do áudio e data)" para uma melhor organização dentro do aplicativo e para futura edição e montagem (Figura 5).

A ausência de estrutura em meus depoimentos para tais áudios permitiu que em alguns deles houvesse divagações reflexivas e poéticas sobre os conceitos que permeiam a criação do filme em processo e a pesquisa que o permeia. Com frequência nos áudios, falei sobre as ideias que apareciam nas orientações, meus planos relativos às etapas de gravação (visita na locação, realização de stills etc.) e detalhes relativos à minha própria história. Aspectos decorrentes da criação de uma obra artística e partícipes de um projeto poético que:

${ }^{10}$ SALLES C. A. . Gesto Inacabado: Processo de Criação Artística. São Paulo: Annablume, 2008, p. 29. 
[...] está localizado em um espaço e um tempo que inevitavelmente afetam o artista. Os documentos de processo, muitas vezes, preservam marcas da relação do ambiente que envolve os processos criativos e a obra em construção [...] São registros da inevitável imersão do artista no mundo que o envolve. (SALLES, 2008, p. 37)

Durante o processo, minha relação com o mundo tem se expandido em sentido físico (através de atividades físicas) e contemplativo (através de contato próximo à natureza). Estes aspectos atravessam meu processo criativo no que tange ao local o qual escolhi gravar, minha relação com ele e sua relação com seu entorno. Uma casa em ruínas pode ser considerada como um ruído na paisagem e pode ao mesmo tempo refletir a passagem do tempo de forma concreta. E ao passo em que gravava as imagens e áudios, notei que a forma documental selecionada para registro deste processo "é pessoal, uma vez que há um modo particular de interação [...]" e surge carregada de experiências individuas que obtive na criação de outras peças audiovisuais e mesmo no acúmulo inconsciente do que chamo de rascunhos em áudio e vídeo. As audiovideonotas retratam a interação que desenvolvo com o ambiente no qual gravo e a poesia que ali identifico: "A experiência estética em arte está relacionada à especificidade de seu material, ao fazer e ao fruir artísticos". ${ }^{11}$ As características de individualidade que carreguei para o processo criativo, em especial nos meios de documentação de processo, o aproxima de uma singularidade que é comum a cada trajetória de criação.

\begin{tabular}{|c|c|}
\hline $\begin{array}{l}\text { diário projeto \#3 28.04.2021.wav } \\
\text { April 28, 9:54 PM }\end{array}$ & $\begin{array}{r}05: 23 \\
27.2 \mathrm{MB}\end{array}$ \\
\hline translúcida .wav & 02:40 \\
\hline April 21, 9:30 PM & $13.5 \mathrm{MB}$ \\
\hline nova diferenciado .wav & 02:49 \\
\hline April 20, 11:48 AM & $14.3 \mathrm{MB}$ \\
\hline diário projeto \#2 08.04.2021.wav & 03:17 \\
\hline April 10, 6:48 PM & $16.6 \mathrm{MB}$ \\
\hline My recording 124.wav & $02: 50$ \\
\hline April 9, 11:53 AM & $14.3 \mathrm{MB}$ \\
\hline diário projeto \#1 02.04.2021.wav & 05:00 \\
\hline April 2, 5:21 PM & $25.2 \mathrm{MB}$ \\
\hline
\end{tabular}

Figura 5. Autoria própria, Screenshot da tela do aplicativo com arquivos de áudio, 2021.

\footnotetext{
${ }^{11}$ PIMENTEL L. G., Processos artísticos como metodologia de pesquisa. Revista OuvirOuver, Uberlândia, 2015, p. 93-94.
} 
revista de crítica genética

A utilização da fala nos áudios permite fluidez de ideias no registro do processo em questão. De forma análoga a um diário, registro periodicamente os aspectos relevantes ao processo criativo de 190_lfa, a fim de arquivá-los e agregá-los ao decorrer e ao final do processo para a composição das audiovideonotas.

\subsection{Video}

As imagens variam, assim como no caso de Jonas Mekas, entre temas relativos ao trabalho e a registros de momentos variados do processo criativo - desde momentos em que estou na locação em que gravo o filme, me relacionando fisicamente com o espaço, até momentos de contemplação da natureza e da casa em ruínas, até situações do cotidiano como caminhar e os tempos de pausa entre as tarefas diárias: momentos de reflexão sobre a criação (Figuras 6, 7 e 8). As gravações das imagens ocorrem de forma aleatória, principalmente nos momentos em que vou à casa. Desta forma, operam como extensão de minha visão sobre o local e como uma janela para os caminhos pelos quais transito. Nestes momentos quase sempre estou sozinho e por consequência me coloco em estado meditativo para ponderar sobre o próprio espaço, sobre os restos de destroços abundantes ali, sobre a história dessa casa, a impressão do tempo sobre o espaço; nos momentos de gravação, percebo a amplitude do som no local inabitado, as peculiaridades estéticas que os destroços agregam às imagens arquivadas. Muitas são as relações específicas que cruzam a casa 190 com minha pesquisa de forma mais abstrata, quase sensorial. Utilizando de registros fortemente pessoais, percebo que estabeleço conexão próxima à obra que estou criando.

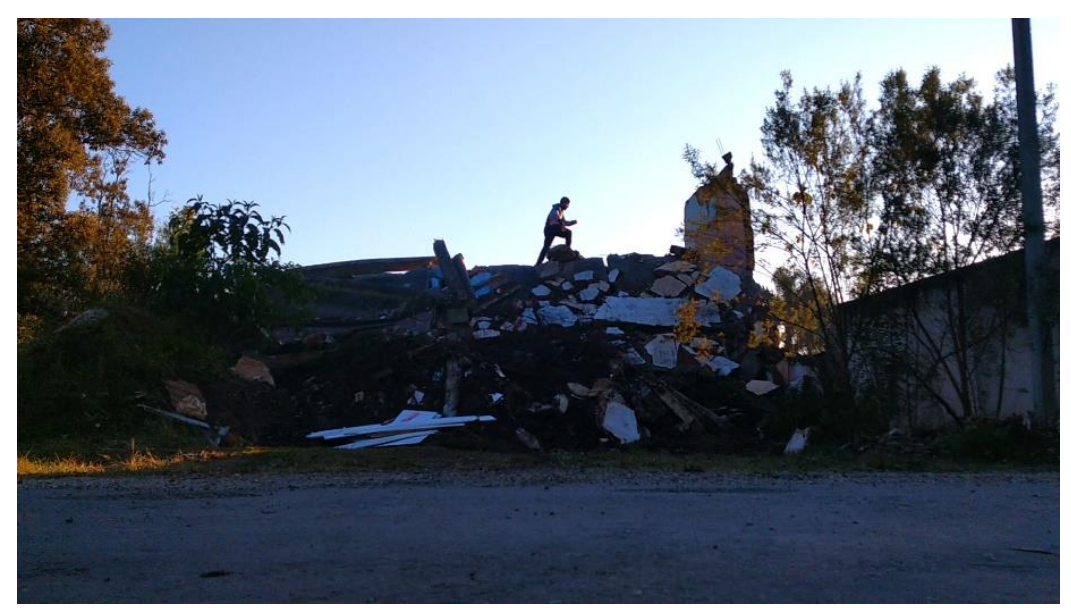

Figura 6. Autoria própria, frame de um dos documentos de processo, 2021. 


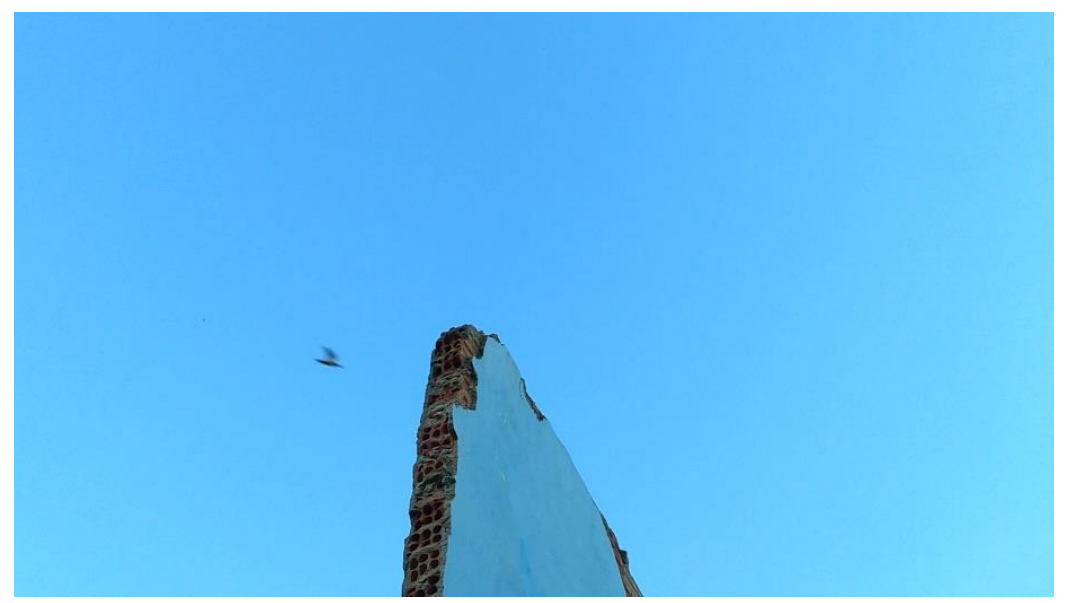

Figura 7. Autoria própria, frame de um dos documentos de processo, 2021.

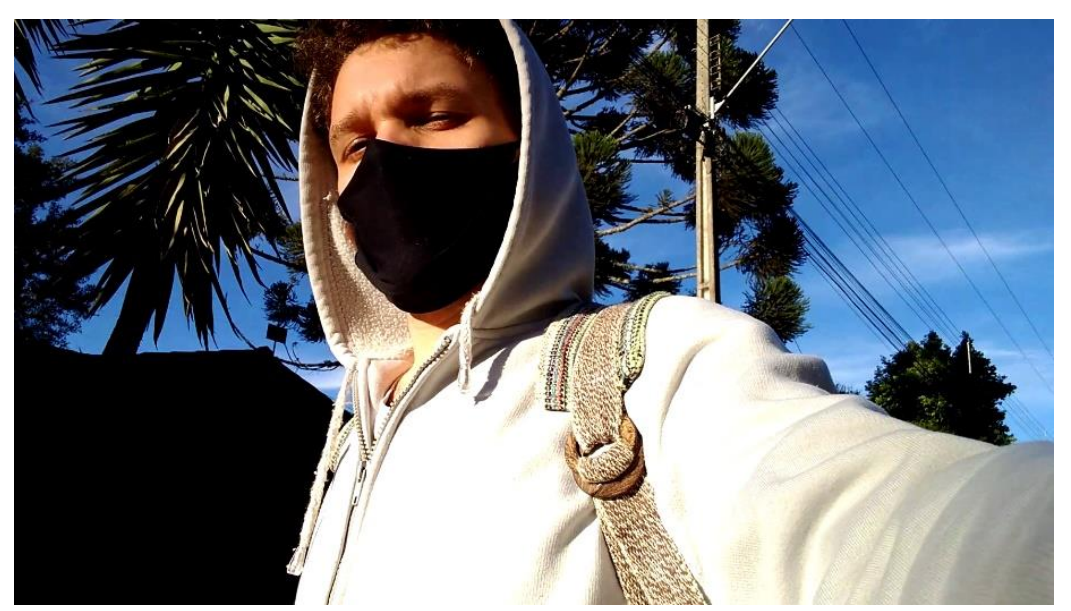

Figura 8. Autoria própria, frame de um dos documentos de processo, 2021.

Utilizo câmera disponível no aparelho celular para realizar a captura dos vídeos, tendo em vista que o celular se mostra como uma alternativa mais leve (do que uma câmera convencional). Este dispositivo carrega um aspecto de ferramenta cotidiana, não só como meio de documentação, mas também como alarme, calendário, agenda etc. O smartphone se tornou tecnologia quase indispensável na segunda década do século XXI ao propiciar todas essas opções corriqueiras e necessárias ao dia-a-dia, e além disso, propiciar formas cada vez mais democráticas para a captura de audiovisual, e que nos levam novamente às imagensdocumento apresentadas. Imagens resultantes da concretização do processo em andamento que transfiguram-se em evidências diretas dos rumos tomados na criação. Da aproximação que suscitamos entre os rascunhos em vídeo e os filmes-diário, percebo semelhança na natureza de ambas formas de capturar o mundo pois "os filmes de Mekas transitam entre um impulso de cunho documental como registrar o real e, ao mesmo tempo, explora a subjetividade do autor no sentido de pensar o seu próprio processo [...]"12. A

${ }^{12}$ GUTFREIND, C. F., VALLES R. A. A construção da autorrepresentação nos filmes-diário de Jonas Mekas. Galáxia (São Paulo, online), 2017, p. 36. 
revista de crítica genética

documentação de processo demonstra o histórico da obra em criação em associação às características da realidade do criador.

Ao se aproximarem ao real que capturam em suas lentes, as câmeras transfiguram os momentos do processo em novas formas de existência a partir das imagens, pensadas através do dispositivo videográfico e da lógica digital. Ao passo em que o artista possui liberdade para interpretá-las e reconfigurá-las em novos formatos segundo seu próprio percurso criativo.

\section{Aplicação da audiovideonota: o processo criativo inserido na criação}

Inicialmente, observamos aquilo que Cecília Salles conceitua como 'documentos de processo', ou seja, aqueles documentos, materiais que vêm a apresentar o percurso do trajeto daquele que cria, os quais: "[...] São retratos temporais de uma gênese que agem como índices do percurso criativo" ${ }^{13}$. Os documentos de processo não exprimem exatamente o processo mental do sujeito criador pois são de outra natureza. Portanto tais registros processuais podem ser realizados de maneira livre, sem prescrição determinada. $\mathrm{O}$ artista pode utilizar as mídias que possui mais afinidade: anotações, diário, áudios etc. Nota-se a característica de restos, rastros, vestígios da criação em processo, não do processo em si. Justifico minha própria documentação de processo através do ato de gravar: apesar de ser um processo em grande parte mental - as etapas da criação em audiovisual são com frequência muito bem elaboradas antes do início das gravações, passando por várias etapas como roteiro, decupagem etc. - o audiovisual traz consigo a referência imagética e visual daquele que filma. Salles afirma que:

[...] o percurso criativo conhece uma lenta definição do projeto poético do artista. [...] Pode-se, assim, dizer que o processo de criação de uma obra é a forma do artista conhecer, tocar e manipular seu projeto de caráter geral. Cada obra é uma possível concretização do grande projeto que direciona o artista. Se a questão da continuidade for levada às últimas consequências, pode-se ver cada obra como um rascunho ou concretização parcial desse grande projeto. (SALLES, 2008, p. 39).

Já há muitos anos, desde que adquiri meu primeiro telefone celular com câmera, tenho o costume de utilizar a ferramenta para coletar fotografias e vídeos de variados detalhes e acontecimentos do cotidiano. Tratam-se de imagens do céu, de manchas em lugares variados, de insetos, de caminhadas. Estes vídeos acabam por vezes a formar parte de trabalhos audiovisuais que tenho criado ao longo dos anos. Ao decorrer do tempo passei a tratar essas imagens como rascunhos audiovisuais que carregam um valor em si e podem vir a agregar em algum trabalho específico. Até o ponto em que, no início do período pandêmico, decidi realizar um conjunto de minidocumentários somente captando imagens de minha própria rotina e de minha casa. Os nomeei por 'trilogia qvarentena' e os publiquei em mídias sociais como trabalhos audiovisuais que

${ }^{13}$ SALLES C. A. Gesto Inacabado: Processo de Criação Artística. São Paulo: Annablume, 2008, p. 17. 
revista de crítica genética

trazem esse aspecto pessoal das gravações aleatórias com potencial de se transformarem em obras completas. A percepção da possibilidade deste uso gerou a vontade de buscar alternativas para usar estas imagens.

Para a documentação de processo de 190_lfa, passei a registrar intencionalmente momentos em que me locomovia para a casa em ruínas, assim como caminhadas pelos arredores e imagens pelo local. Estes vídeos operam de forma semelhante a rascunhos para um pintor, ajudando-me a observar o percurso que passei na criação de determinado filme. Retornando ao conceito do projeto poético do artista, Salles sugere que a obra finalizada se caracteriza como um rascunho do trabalho completo do artista ${ }^{14}$. Em sentido análogo, coloco os rascunhos em vídeo como fragmentos componentes de um trabalho mais amplo e também os relaciono com a conceituação do projeto poético de Salles na medida em que agrego estes arquivos - que já possuem recorrência em outras obras que realizei como na 'trilogia qvarentena' - e os transformo em uma possibilidade de registro de processo. No projeto poético, cada obra compõe parte do trabalho geral do artista, assim como aspectos formais recorrentes também compõe parte de seu projeto estético - e por extensão poético. Assim, a ideia de documentação de processo através de arquivos audiovisuais é a hipótese que abordo ao decidir gravar imagens e sons como traços do percurso criativo.

Para compreendermos o processo criativo referido, é importante que haja uma explicação do que consiste a obra idealizada. A obra audiovisual denominada 190_lfa se caracteriza como um híbrido entre conceitos: do documentário poético à música visual; do trabalho com vídeo ao álbum conceito. No trabalho, realizo planos estáticos de uma casa em ruínas, que irá nomear o trabalho: 190 é seu número e 'lfa' funciona como acrônimo à rua em que vivo, Rua Leonídia Ferreira Alves. A criação sonora se dará a partir da junção dos chamados 'field recordings' (denominação dada ao subgênero de música ambiente que privilegia gravações diretas de locais, nas quais ouvimos sons correspondentes) ao conceito de paisagem sonora, amplamente estudado em audiovisual e na criação musical como um todo, dentro do gênero amplo da música ambiente.

É aliada à proposição da necessidade da criação artística de parte do criador que proponho também a criação de arquivos audiovisuais como documentação de processo e de metodologia de estudo de processo. Lúcia Gouvea Pimentel postula que: “Ao constituir um corpo teórico com critérios de credibilidade, análise conceitual, análise crítica e análise inferencial, @ pesquisador@ em ou sobre Arte constrói o alicerce para novas propostas de pesquisa a partir do seu registro [...]”. Noto que, a partir de bases epistemológicas e artísticas estabelecidas, é possível pensar arte como metodologia, pois: "Pesquisar arte é também um momento de criação." ${ }^{15}$. Podemos sugerir então a possibilidade do processo artístico como método de pesquisa.

\section{Considerações finais}

A utilização dos dispositivos em áudio e vídeo com intuito de comprovar o processo criativo de 190_lfa ainda não demonstra seu pleno potencial tendo em vista que nos referimos a um processo específico em

\footnotetext{
${ }^{14}$ SALLES C. A. Gesto Inacabado: Processo de Criação Artística. São Paulo: Annablume, 2008, p. 39.

${ }^{15}$ PIMENTEL L. G., Processos artísticos como metodologia de pesquisa. Revista OuvirOuver Uberlândia, 2015, p. 97.
} 
revista de crítica genética

movimento. Entretanto, como sujeito criador desta obra, utilizo a audiovideonota devido a sua adequação ao projeto audiovisual. A capacidade de transmitir sensações e relações espaciais em arquivos é ampliada com o registro audiovisual se comparado a anotações, gravações em áudio isoladas ou mesmo fotos. O objetivo ao desenvolver esta forma para documentar o processo criativo é de procurar apreender cada particularidade do processo em sua completude, mesmo reconhecendo a impossibilidade deste feito. $\mathrm{O}$ processo criativo envolve a realidade do artista e uma abundância de aspectos relativos à sua obra. Já a documentação de processo aponta algumas especificidades do caminho tomado no curso da criação, em vista da compreensão de como este mesmo processo ocorreu. Algo ainda potente no uso das imagens para documentação é a inscrição visual das mudanças que ocorrem na ruína 190 quase diariamente por interferência de vizinhos ou mesmo outras pessoas que ocupam o espaço momentaneamente. Associando imagens e áudios ampliamos a possibilidade de conexões entre documentos diversos e que derivam de mídias diferentes no intuito não somente de tornar compreensível o percurso criativo mas também de ressaltar alguns de seus aspectos que podem não ser aparentes em formas de documentar que utilizem de mídias isoladas.

A audiovideonota é desenvolvida como consequência espontânea e pessoal da necessidade de haverem arquivos comprovativos do processo criativo em andamento. Parto da possibilidade da criação artística como preceito metodológico e o aproximo aos documentos de processo indicados por Cecília Salles, aos filmes-diário de Jonas Mekas, convergindo assim na proposta da audiovideonota. Unindo imagens em movimento e sons inerentes a meu processo artístico, apresento e proponho a forma de documentação que tem se mostrado adequada às situações e etapas decorrentes da criação.

\section{Referências}

DELEUZE, G. O ato de criação. Palestra proferida em Paris em 1987, transcrita e publicada em Folha de São Paulo, 27 jun. 1999, Caderno Mais!, p. 4-5;

FORTIN, S. Contribuições possíveis da etnografia e da auto-etnografia para a pesquisa na prática artística. Revista Cena, n. 7, 2009. Disponível em: <https://seer.ufrgs.br/cena/article/view/11961/7154>. Acesso em: 27 jul. 2021;

GUTFREIND, C. F.; VALLES, R. A construção da autorrepresentação nos filmes-diário de Jonas Mekas. Galáxia (São Paulo, online), n. 36, set-dez., p. 31-44, 2017. Disponível em: <https://revistas.pucsp.br/index.php/galaxia/article/view/31943/24115>. Acesso em: 23 jul. 2021;

MARASCHIN, L. T. et al. Latim básico. $1^{\text {a }}$ ed. Santa Maria, RS: UFSM, NTE, UAB, 2013. Disponível em: <https://repositorio.ufsm.br/bitstream/handle/1/16403/Curso_Let-Portug-Lit_LatimBasico.pdf?sequence $=1 \&$ isAllowed $=y>$. Acesso em: 24 jul. 2021;

MEKAS, J. O filme-diário. In.: Jonas Mekas / Patrícia Mourão (org.). - São Paulo: Centro Cultural Banco do Brasil; Pró-reitoria de Cultura e Extensão Universitária - USP, 2013. Disponível em: $<$ https://www.bb.com.br/docs/pub/inst/dwn/jonasmekas.pdf >. Acesso em: 20 jun. 2021; 
revista de crítica genética

MOURÃO, P. Salve Jonas. In.: Jonas Mekas / Patrícia Mourão (org.). - São Paulo: Centro Cultural Banco do Brasil; Pró-reitoria de Cultura e Extensão Universitária - USP, 2013. Disponível em: $<$ https://www.bb.com.br/docs/pub/inst/dwn/jonasmekas.pdf>. Acesso em: 20 jun. 2021;

PIMENTEL, L. G. Processos artísticos como metodologia de pesquisa. Revista OuvirOuver, 11(1), pp. 88-98, Uberlândia: UFU, $2015 . \quad$ Disponível em: <http://www.seer.ufu.br/index.php/ouvirouver/article/view/32707>. Acesso em: 23 jun. 2021;

SALLES, C. A. Gesto Inacabado: Processo de Criação Artística. São Paulo: Fapesp. Editora: Annablume, 2008;

SONG of Avignon. Direção: Jonas Mekas. Produção: Jonas Mekas. Estados Unidos: 1998;

VALLES, R. R. Narrar o vivido, viver o narrado: a construção do diário na obra de Jonas Mekas. 2018, 226 p. Tese (Doutorado) - Programa de Pós-Graduação em Comunicação Social, PUCRS. Porto Alegre, 2018. 